Article

\title{
Fatigue Life Assessment in Bainitic Steels Based on The Cumulative Strain Energy Density
}

\author{
Rui F. Martins ${ }^{1, *(\mathbb{D}}$, Ricardo Branco ${ }^{2}\left(\mathbb{D}\right.$ and Xiaoyan Long ${ }^{3}$ \\ 1 UNIDEMI, Department of Mechanical and Industrial Engineering, Nova School of Science and Technology, \\ Universidade NOVA de Lisboa, 2829-516 Monte de Caparica, Portugal \\ 2 Department of Mechanical Engineering, University of Coimbra, CEMMPRE, Rua Luís Reis Santos, \\ Pinhal de Marrocos, 3030-788 Coimbra, Portugal; ricardo.branco@dem.uc.pt \\ 3 State Key Laboratory of Metastable Materials Science and Technology, Yanshan University, \\ Qinhuangdao 066004, China; longxy@ysu.edu.cn \\ * Correspondence: rfspm@fct.unl.pt; Tel.: +351-21-294-8567
}

Received: 7 October 2020; Accepted: 29 October 2020; Published: 3 November 2020

check for updates

\begin{abstract}
Carbide-free bainitic steels are an example of high-strength steels that show an excellent combination of strength, ductility, toughness and rolling fatigue contact resistance and are progressively being introduced in the production of railways, crossings and automotive components. Although there are Mn-free approaches able to produce carbide-free bainitic steels, those based on the addition of Mn are less expensive. Therefore, it is important to fully understand the mechanical behavior of such materials to develop reliable engineering products. In this paper, three low-carbon bainitic steels, differing in Mn content, namely $0 \%, 2.3 \%$ and $3.2 \%$, designated as steel A, B and $\mathrm{C}$, respectively, were studied in a systematic manner. Low-cycle fatigue tests were conducted under symmetrical strain-controlled conditions for different strain amplitudes $(0.6 \%, 0.7 \%, 0.8 \%$ and $1 \%$ ). Independent of Mn content, a strong relationship between cumulative strain energy density and number of cycles to failure was found. Based on this relationship, a new predictive model, capable of estimating the fatigue lifetime, was developed. Predictions based on the new model were close to the experimental lives and were more accurate than those computed via the well-known Smith-Watson-Topper (SWT) and Liu criteria.
\end{abstract}

Keywords: high-strength bainitic steels; Mn effect; strain energy density; fatigue life predictions

\section{Introduction}

Diminishing fuel consumptions and mandatory lower $\mathrm{CO}_{2}$ emissions are both pushing the automotive industry to weight reduction in the design of cars and increasing the use of railway transportation of goods and people. Therefore, to achieve those goals, recently advanced high-strength steels are currently being used to reduce components' thicknesses in the automotive industry and to produce improved railway rails and crossings.

In fact, carbide-free bainitic steels are an example of these new materials which show an excellent combination of strength, ductility and toughness that satisfies demands of high-strength steels in various industrial applications [1,2]. Moreover, bainite covers some different microstructures, from the classical upper and lower bainite to the carbide-free structures found in lower carbon steels [3], and is produced from the transformation of austenite at temperatures below the pearlite range and above the martensite starting temperature [4]. In the production of bainitic steel, it is paramount that perlite and ferrite regions be pushed as far to the right as possible on the continuous cooling transition diagram to allow for bainitic formation, and alloying elements such as nickel, molybdenum, manganese and chromium are selected for this purpose [4]. Besides, the high silicon content of $1.3 \mathrm{wt} \%$ suppresses the 
formation of brittle cementite from austenite during bainitic transformation [5], and the addition of $\mathrm{Al}$ alloying element also decreases hydrogen embrittlement [2]. Similar to $\mathrm{Si}, \mathrm{Al}$ suppresses cementite precipitation [6] and consequently produces a carbide-free bainitic microstructure-referring to the absence of cementite in between bainitic ferrite laths [5], which improves the toughness and rolling contact fatigue (RCF) resistance of the steels, also crucial for sustainable material design [5].

Concerning the loadings, automotive components and railway rails are being subjected to very complex and demanding loadings, requiring suitable bainitic steels with high yield strength to avoid severe plastic deformation, high toughness, strain hardening capability, and wear resistance, and improved RCF properties [7] in order to avoid, as much as possible, the nucleation and growth of fatigue cracks. Moreover, dynamic cyclic loadings are frequently applied; hence, low-cycle and high-cycle fatigue regimes are worth investigating [8,9], since improved fatigue life has a significant effect on safety, reliability and profitability. Additionally, fatigue crack growth rates in bainitic steels are revealed to be lower than in traditional pearlitic rail steels [10].

Therefore, the influence of Mn content in the cyclic mechanical properties of bainitic steels is of great importance to developing durable components. In this paper, three high-strength bainitic steels were studied. Elastic and plastic strain energy densities were calculated during the entire life of the specimens tested under fully reversed strain-controlled conditions and were associated with the resilience and fatigue toughness of the tested materials. Finally, fatigue life was evaluated by means of a cumulative strain energy density model and the predictions were compared to those obtained via the well-known SWT and Liu criteria.

\section{Materials and Methods}

The chemical composition of each high-strength low-carbon bainitic steel under study, referred to as steels A, B and C, is presented in Table 1. As clearly seen, Mn content varied from $0 \%$ to $3.2 \%$, while the other chemical elements were maintained constant. Static and cyclic mechanical properties, which depend on microstructure [9], were obtained for the three materials through monotonic axial tensile and low-cycle fatigue tests, respectively (see Tables 2 and 3).

Table 1. Chemical compositions of tested steels ( $w \mathrm{t} \%$ ) (Data from [6]).

\begin{tabular}{ccccccccc}
\hline Steel & C & Si & Mn & Cr & Ni & Mo & Al & Fe \\
\hline A & 0.26 & 1.6 & 0 & 1.9 & 0.4 & 0.3 & 0.6 & Bal. \\
B & 0.27 & 1.7 & 2.3 & 1.9 & 0.4 & 0.4 & 0.7 & Bal. \\
C & 0.27 & 1.7 & 3.2 & 1.9 & 0.4 & 0.4 & 0.7 & Bal. \\
\hline
\end{tabular}

Table 2. Monotonic mechanical properties of the tested steels (Data from [6,9]).

\begin{tabular}{cccc}
\hline Property & Steel A & Steel B & Steel C \\
\hline Yield Strength, $\sigma_{\text {YS }}[\mathrm{MPa}]$ & 784 & 1133 & 1230 \\
Tensile Strength, $\sigma_{\mathrm{UTS}}[\mathrm{MPa}]$ & 1150 & 1540 & 1611 \\
Total elongation, $\Delta \mathrm{L}_{\mathrm{t}}[\%]$ & 18.3 & 14.7 & 13.0 \\
Young's Modulus, $E[\mathrm{GPa}]$ & 197.6 & 198.2 & 198.8 \\
\hline
\end{tabular}

Table 3. Low-cycle fatigue properties of the tested steels (Data from [9]).

\begin{tabular}{cccc}
\hline Property & Steel A & Steel B & Steel C \\
\hline Fatigue strength coefficient, $\mathrm{f}^{\prime}[\mathrm{MPa}]$ & 1585 & 2029 & 2501 \\
Fatigue strength exponent, $\mathrm{b}$ & -0.0721 & -0.06885 & -0.074 \\
Fatigue ductility coefficient, $\mathrm{f}^{\prime}$ & 0.7432 & 1.9401 & 0.201 \\
Fatigue ductility exponent, $\mathrm{c}$ & -0.608 & -0.8167 & -0.5535 \\
Cyclic hardening coefficient, $k^{\prime}(\mathrm{MPa})$ & 1684 & 1931 & 3085 \\
Cyclic hardening exponent, $\mathrm{n}^{\prime}$ & 0.1172 & 0.0722 & 0.1330 \\
\hline
\end{tabular}


The fatigue tests were performed under a strain-controlled mode with strain amplitudes, De/2, of $0.6 \%, 0.7 \%, 0.8 \%$ and $1 \%$, using sinusoidal waveforms (strain ratio, $\mathrm{R}=-1$ ), with the aid of a mechanical extensometer, model MTS 634.31F-24, directly clamped to the gauge section in an MTS (MTS Systems Corporation, Eden Prairie, MN, USA) servo-hydraulic testing machine equipped with a $10 \mathrm{kN}$ capacity load cell for a constant strain rate $\left(d \varepsilon / \mathrm{dt}=6 \times 10^{-3} \mathrm{~s}^{-1}\right)$. The specimens were machined and polished according to the specifications outlined in ASTM E606 and had a gauge section with a length of $10 \mathrm{~mm}$ and a diameter of $5 \mathrm{~mm}$. The tests were initiated in compression and stopped when total failure occurred. During the test, the hysteresis loops were stored when the stress range of a given cycle altered more than $5 \%$ with respect to the previous recorded cycle, resulting typically between 50 and 65 hysteresis loops for each strain amplitude applied. Moreover, at least 200 points were saved for each hysteresis loop.

Spline-based techniques were used for data interpolation and smoothing of all hysteresis loops recorded during low-cycle fatigue tests, namely cubic and thin plate splines. Then, numerical integration was carried out to determine the values of elastic strain energy density per cycle $(\Delta W e)$ and plastic strain energy density per cycle $(\Delta W p)$ of the tested steels (see Figure 1$)$. Total strain energy density per cycle $(\Delta \mathrm{Wt})$ was defined as the sum of both components.

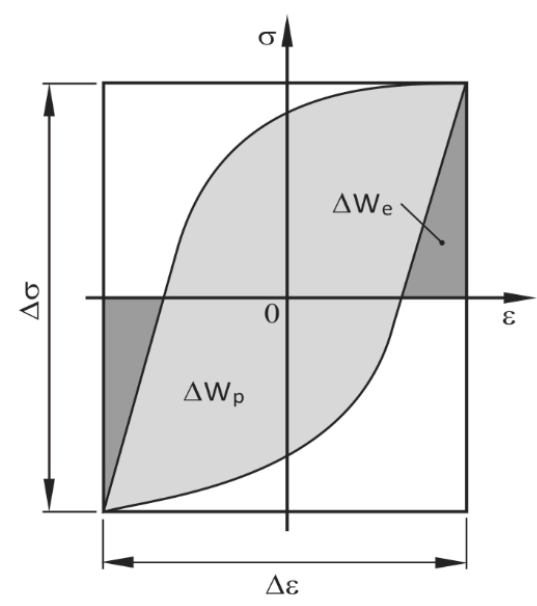

Figure 1. Graphical definition of elastic strain energy density (darker grey areas) and plastic strain energy density (light grey area) considered in the calculations.

Concerning fatigue life predictions, apart from the new proposed predictive model, the SWT model [11], as well as the Liu model [12], were used. In the case of the former, the damage parameter is based on the maximum tensile stress applied on a critical plane and the strain amplitude acting on the same plane (Equation (1)); regarding the Liu model (Equation (2)), which is based on the virtual strain energy applied, DW, it takes into account both elastic and plastic strain energy densities of the hysteresis loops collected in fatigue experiments.

$$
\begin{gathered}
\sigma_{\max } \frac{\Delta \varepsilon}{2}=\frac{\sigma_{f}^{\prime 2}}{E}\left(2 N_{f}\right)^{2 b}+\sigma_{f}^{\prime} \varepsilon_{f}^{\prime}\left(2 N_{f}\right)^{b+c} \\
\Delta W=\Delta \sigma \Delta \varepsilon=\frac{4 \sigma_{f}^{\prime 2}}{E}\left(2 N_{f}\right)^{2 b}+4 \sigma_{f}^{\prime} \varepsilon_{f}^{\prime}\left(2 N_{f}\right)^{b+c}
\end{gathered}
$$

\section{Results}

\subsection{Cumulative Strain Energy Density}

Low-cycle fatigue behavior of the tested steels under symmetrical strain-controlled conditions for a strain amplitude of $1.0 \%$ is presented in Figure 2. As shown, the cyclic stress-strain responses were 
significantly different for the three materials. Overall, it was clear that the stress range associated with this strain level increased with higher Mn contents.

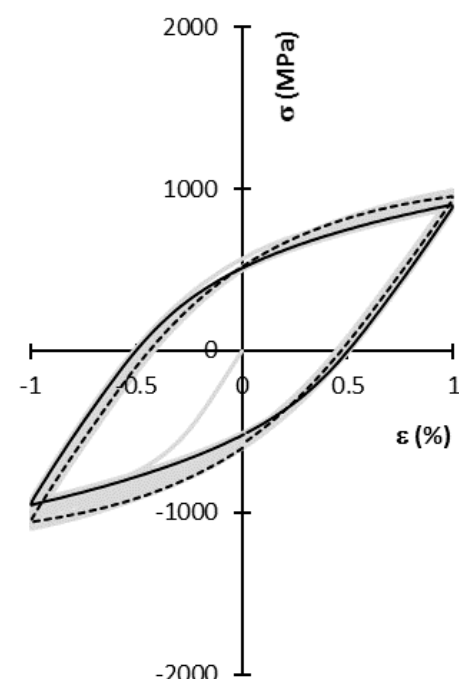

(a)

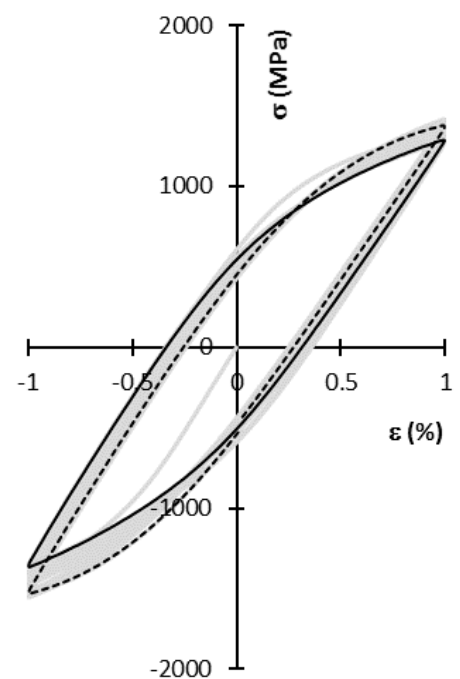

$-2000$

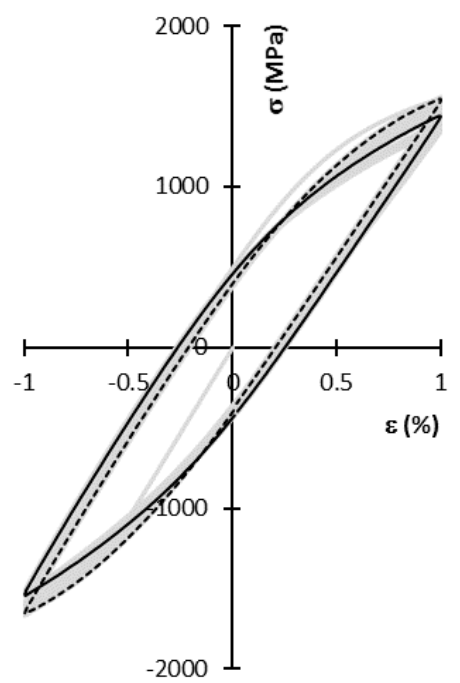

(c)

Figure 2. Cyclic stress-strain response of: (a) steel A; (b) steel B; and (c) steel C (Data from [9]).

Moreover, irrespective of the tested steel, the shapes of the hysteresis loop changed significantly throughout the lifetime. These changes were particularly evident by comparing the second and the mid-life loops. Since the uncontrolled stress range reduced over time, the three materials exhibited a cyclic strain-softening behavior for this strain level. Literature suggests that at lower strain amplitudes Steel C maintains a similar trend, but Steel A and Steel B tend to strain-harden [9].

Figure 3 plots elastic and plastic strain energy densities against the number of cycles for different strain amplitudes. These variables, as can be seen, were relatively constant along time. In most cases, the curves present three main stages: a short initial period with rapid changes; a dominant saturated stage with stable values; and a final stage, close to total failure, characterized by sudden changes. As expected, elastic and plastic strain energy densities per cycle increased with strain amplitude. On the other hand, at a given strain amplitude, the values of $\Delta W e$ and $\Delta W p$ depended on the tested steel, which agreed with the hysteresis loop shapes displayed in Figure 1.

At a fixed value of strain amplitude, a close analysis of the results showed that plastic strain energy density per cycle was higher for steel A and tended to diminish as Mn content increased, except for $\Delta \varepsilon / 2=0.6 \%$, where steel $C$ exhibited higher plastic strain energy density values than steel B.

As far as elastic positive strain energy density is concerned, opposite behavior was observed, i.e., the maximum values at a given strain amplitude were found for steel $C$. Furthermore, $\Delta W e$ increased for lower contents of $\mathrm{Mn}$, except for $\Delta \varepsilon / 2=0.6 \%$, where steel A had higher plastic strain energy density than steel B.

Figure 4 plots cumulative elastic $(\mathrm{We})$, plastic $(\mathrm{Wp})$ and total $(\mathrm{Wt})$ strain energy densities as a function of strain amplitude. The computed values of the aforementioned variables are listed in Table 4 , as well as the three components of strain energy density of the mid-life cycle, identified as $\Delta W e_{\text {, }} \mathrm{ML}$, $\Delta \mathrm{W} \mathrm{p}_{\mathrm{ML}}$ and $\Delta \mathrm{Wt}, \mathrm{ML}$. At first sight, it could be concluded that steel A without $\mathrm{Mn}$ revealed higher plastic strain energy densities than elastic strain energy densities for all the strain amplitudes applied, showing a high fatigue toughness capability. On the contrary, the other two steels revealed higher elastic than plastic strain densities, except for steel B at a strain amplitude of $1.0 \%$. 


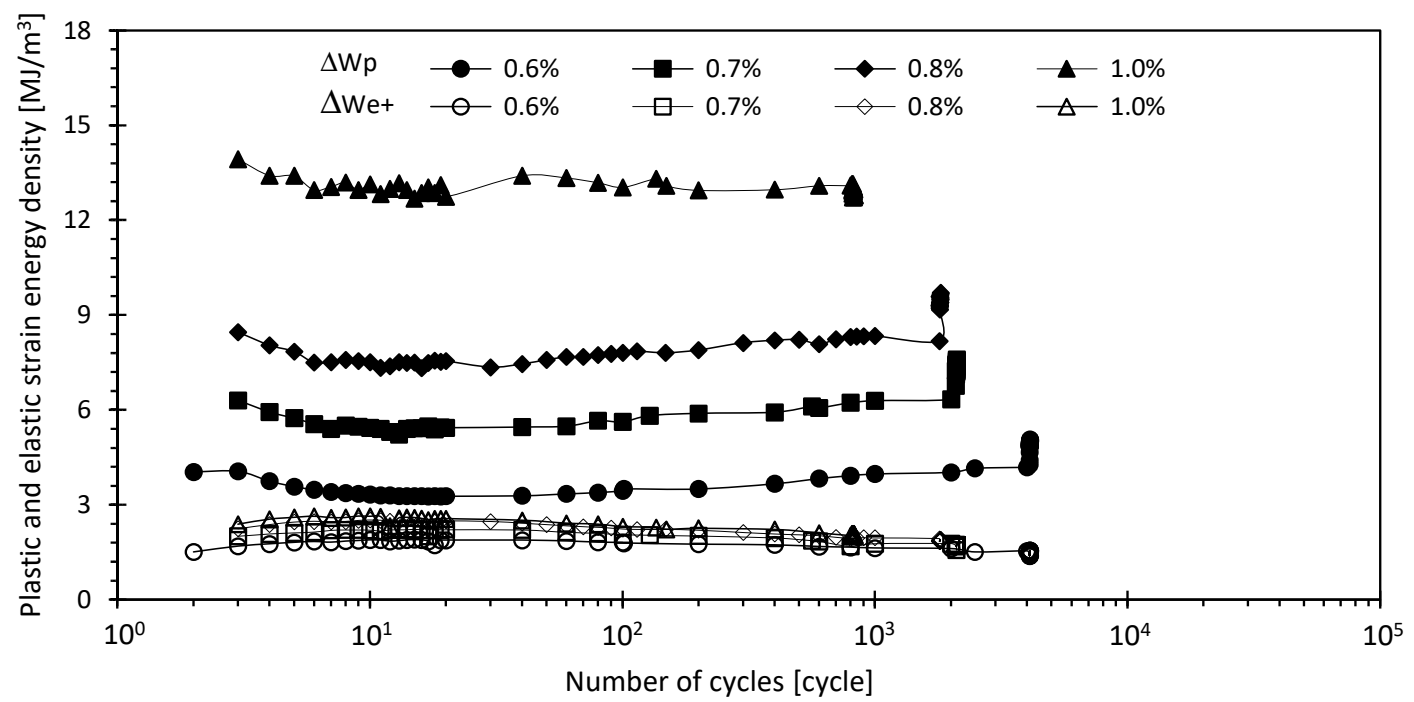

(a)

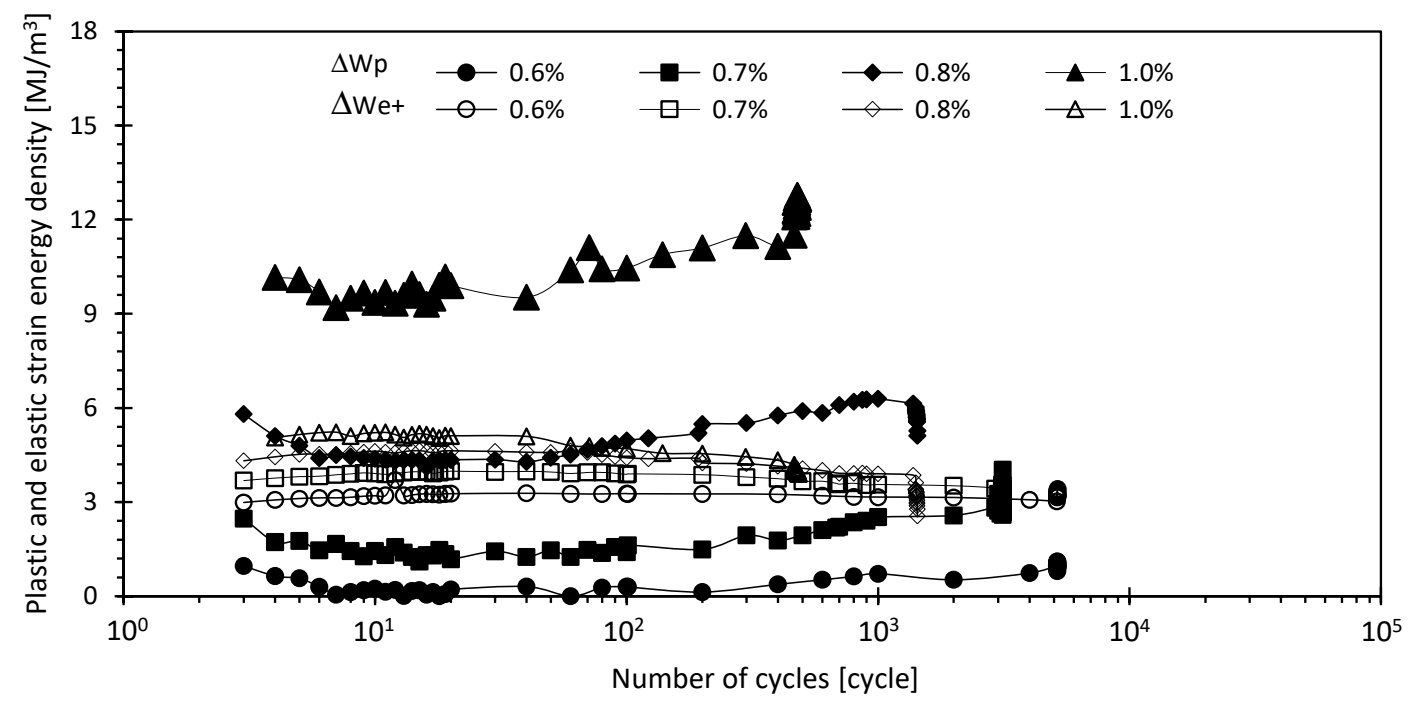

(b)

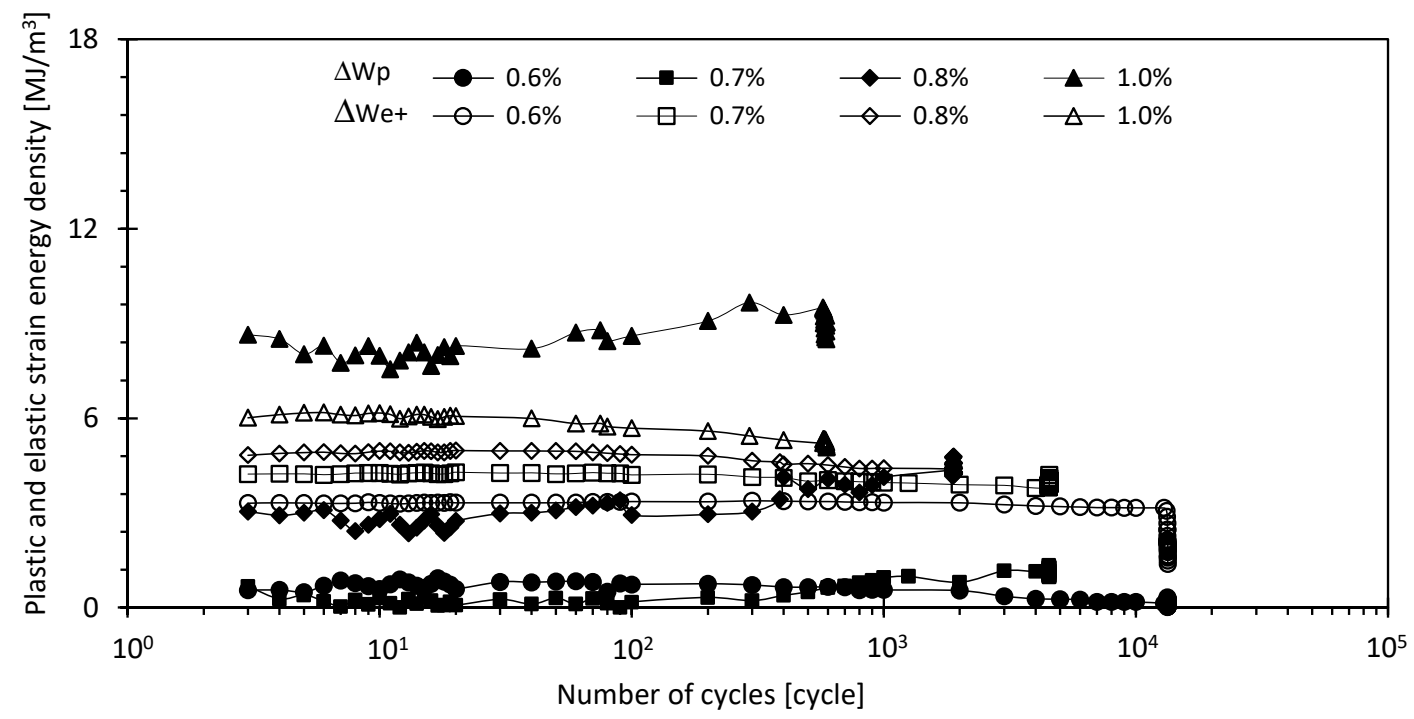

(c)

Figure 3. Plastic $(\Delta \mathrm{Wp})$ and elastic $(\Delta W e)$ strain energy densities per cycle as a function of strain amplitude for: (a) steel A; (b) steel B; and (c) steel C. 

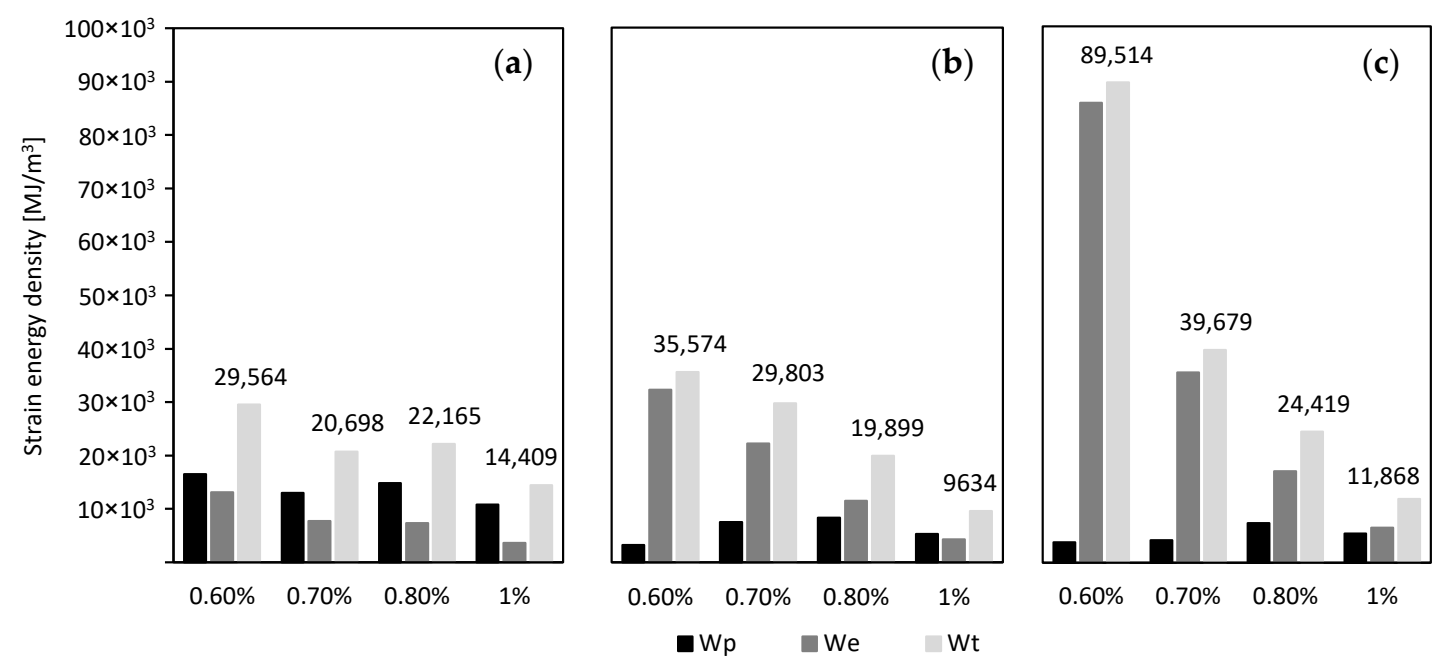

Figure 4. Cumulative plastic $(\mathrm{Wp})$, elastic $(\mathrm{We})$ and total $(\mathrm{Wt})$ strain energy density as a function of strain amplitude for: (a) steel A; (b) steel B; and (c) steel C.

Table 4. Cumulative strain energy densities at the mid-life cycle of the tested steels.

\begin{tabular}{|c|c|c|c|c|c|c|c|}
\hline Material & $\Delta \varepsilon / 2[\%]$ & $W e\left[\mathrm{MJ} / \mathrm{m}^{3}\right]$ & $\mathrm{Wp}\left[\mathrm{MJ} / \mathrm{m}^{3}\right]$ & $\mathrm{Wt}\left[\mathrm{MJ} / \mathrm{m}^{3}\right]$ & $\Delta W e_{, \mathrm{ML}}\left[\mathrm{MJ} / \mathrm{m}^{3}\right]$ & $\Delta \mathrm{W}, \mathrm{pLL}_{\mathrm{ML}}\left[\mathrm{MJ} / \mathrm{m}^{3}\right]$ & $\Delta \mathrm{Wt}, \mathrm{ML}\left[\mathrm{MJ} / \mathrm{m}^{3}\right]$ \\
\hline \multirow[t]{4}{*}{ A } & $0.6 \%$ & 13,099 & 16,465 & 29,564 & 3.09 & 2.66 & 5.75 \\
\hline & $0.7 \%$ & 7686 & 13,012 & 20,698 & 3.57 & 4.01 & 7.58 \\
\hline & $0.8 \%$ & 7314 & 14,851 & 22,165 & 3.96 & 6.26 & 10.22 \\
\hline & $1.0 \%$ & 3631 & 10,778 & 14,409 & 4.47 & 8.14 & 12.61 \\
\hline \multirow[t]{4}{*}{ B } & $0.6 \%$ & 32,271 & 3303 & 35,574 & 6.14 & 1.42 & 7.57 \\
\hline & $0.7 \%$ & 22,220 & 7584 & 29,803 & 6.57 & 3.22 & 9.78 \\
\hline & $0.8 \%$ & 11,527 & 8371 & 19,898 & 7.43 & 5.82 & 13.26 \\
\hline & $1.0 \%$ & 4342 & 5292 & 9634 & 8.79 & 12.68 & 21.48 \\
\hline \multirow[t]{4}{*}{ C } & $0.6 \%$ & 85,723 & 3791 & 89,514 & 6.08 & 0.84 & 6.92 \\
\hline & $0.7 \%$ & 35,458 & 4161 & 39,619 & 7.37 & 2.24 & 9.61 \\
\hline & $0.8 \%$ & 17,046 & 7373 & 24,419 & 8.61 & 4.34 & 12.96 \\
\hline & $1.0 \%$ & 6478 & 5390 & 11,868 & 10.17 & 10.75 & 20.93 \\
\hline
\end{tabular}

It is interesting to note that, at a fixed strain amplitude, steel A presented the greatest values of cumulative plastic strain energy density, similarly to plastic strain energy density per cycle; while steel $C$ exhibited the highest cumulative elastic strain energy density, as with elastic strain energy density per cycle.

Concerning cumulative total strain energy density, $\mathrm{Wt}$, it was possible to conclude that steel $\mathrm{C}$ with higher Mn content disclosed the highest values at strain amplitudes lower than $1.0 \%$, while for $\Delta \varepsilon / 2=1.0 \%$, the highest value was exhibited by steel A. In addition, in a log-log scale, there was a direct proportionality between cumulative total strain energy density and the determined fatigue resistance of the tested steels (see Figure 5). As shown, the data could be successfully fitted by a single power function independent of Mn content and with a high correlation coefficient, which is a major and interesting outcome.

It is also interesting to note that elastic strain energy density of the mid-life cycle $(\Delta W e, \mathrm{ML})$ could be correlated with cumulative strain energy density in log-log scales by means of a straight line, as shown in Figure 6. The values of $\Delta W e, \mathrm{ML}$ are summarized in Table 4 . In this case, unlike cumulative total strain energy density versus the number of cycles to failure, the computed curves did not overlap. In the absence of Mn, the curve was shifted to the left. The increase of Mn content moved the curves to the right. Moreover, the slope tended to decrease as the content of Mn rose. 


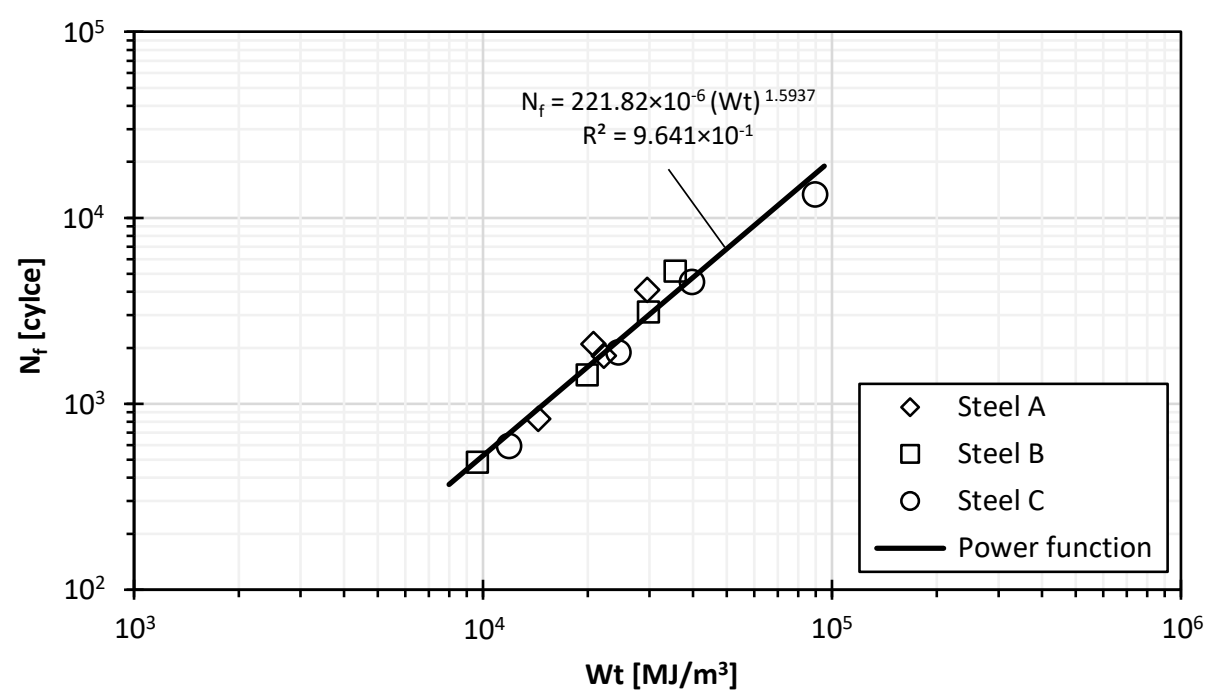

Figure 5. Cumulative total strain energy density $(\mathrm{Wt})$ versus fatigue life $\left(N_{f}\right)$ for the three high-strength bainitic steels under study.

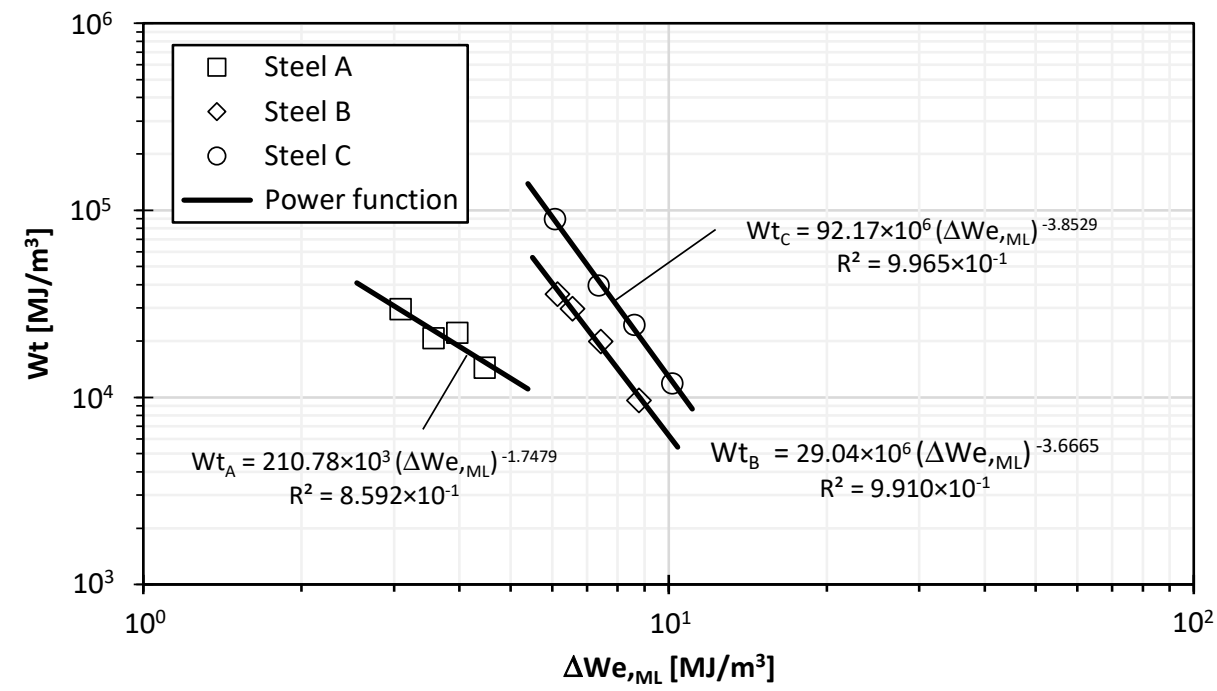

Figure 6. Elastic strain energy density of the mid-life cycle $(\Delta W e, \mathrm{ML})$ against cumulative total strain energy density $(\mathrm{Wt})$ for the three high-strength bainitic steels under study.

\subsection{Fatigue Life Prediction}

Numerical fatigue lives were calculated for the three steels under study and the four strain amplitudes applied in strain-controlled fatigue tests using the well-known SWT model (Equation (1)) and the Liu model (Equation (2)). These calculations were performed with the stress and strain values of the mid-life cycle (see Table 5). After that, numerical results were compared with the obtained experimental data $\left(N_{f}\right)$ listed in Table 5 . For the sake of clarity, a graphical comparison between the predicted and experimental lives is displayed in Figure 7. As can be seen, numerical predictions were almost exact for steel B and resulted in nonconservative values for steel A and steel C. Furthermore, we could conclude that the Liu criterion led to predictions tendentially safer than the SWT criterion. 
Table 5. Fatigue life predictions and experimental fatigue lives.

\begin{tabular}{|c|c|c|c|c|c|c|c|}
\hline Material & $\Delta \varepsilon / 2[\%]$ & $N_{f}[$ cycle] & $\Delta \sigma_{\mathrm{ML}}[\mathrm{MPa}]$ & $\sigma_{\max , \mathrm{ML}}[\mathrm{MPa}]$ & $\mathrm{N}_{\text {SWT }}$ [cycle] & $\mathrm{N}_{\text {Liu }}$ [cycle] & $\mathrm{N}_{\text {CTSED }}$ [cycle] \\
\hline \multirow[t]{4}{*}{$\mathrm{A}$} & $0.6 \%$ & 4104 & 1729.9 & 816.9 & 7398 & 6247 & 2920 \\
\hline & $0.7 \%$ & 2106 & 1822.7 & 875.6 & 3930 & 3536 & 1820 \\
\hline & $0.8 \%$ & 1817 & 1886.9 & 909.6 & 2533 & 2317 & 1535 \\
\hline & $1.0 \%$ & 829 & 1905.7 & 922.5 & 1452 & 1351 & 1192 \\
\hline \multirow[t]{4}{*}{ B } & $0.6 \%$ & 5170 & 2427.2 & 1157.3 & 5082 & 4246 & 3156 \\
\hline & $0.7 \%$ & 3129 & 2483.0 & 1192.4 & 2663 & 2348 & 1658 \\
\hline & $0.8 \%$ & 1432 & 2675.2 & 1299.5 & 1419 & 1318 & 1107 \\
\hline & $1.0 \%$ & 484 & 2754.5 & 1332.6 & 789 & 736 & 666 \\
\hline \multirow[t]{4}{*}{$\mathrm{C}$} & $0.6 \%$ & 13,370 & 2368.6 & 1151.1 & 25,064 & 21,557 & 10,327 \\
\hline & $0.7 \%$ & 4533 & 2637.5 & 1274.5 & 6983 & 5971 & 3592 \\
\hline & $0.8 \%$ & 1896 & 2758.2 & 1344.1 & 3082 & 2774 & 1696 \\
\hline & $1.0 \%$ & 593 & 3096.2 & 1492.6 & 901 & 797 & 640 \\
\hline
\end{tabular}

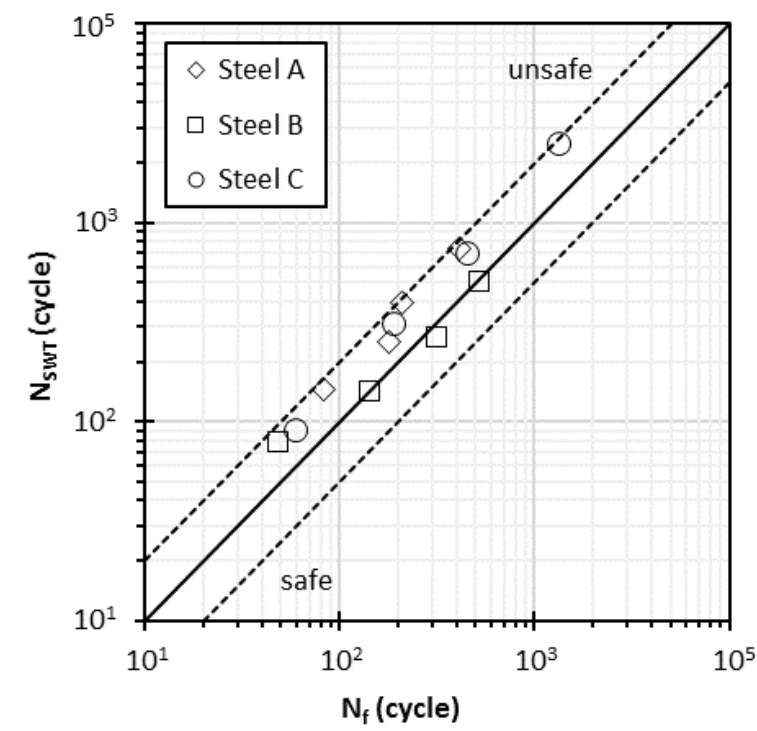

(a)

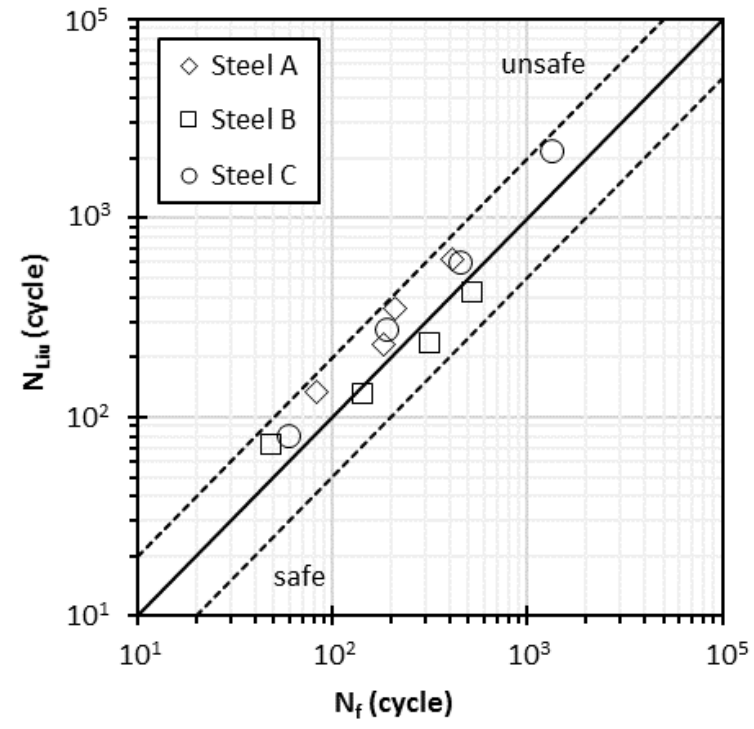

(b)

Figure 7. Comparison between numerical and experimental fatigue lives: (a) SWT criterion; and (b) Liu criterion.

Taking into account some inaccuracies of the tested criteria, a new predictive model, based on the cumulative total strain energy density, was developed. The proposed model lies on energy relationships presented in Section 3.2, more precisely, the power function relating cumulative total strain energy density and the number of cycles to failure (see Figure 5), and the power functions relating elastic strain energy density of the mid-life cycle and the associated cumulative total strain energy density (see Figure 6) found for the high-strength bainitic steels under study.

Regarding the determination of elastic strain energy density, defined here as the sum of both the area associated with the linear portion of the descending branch from maximum stress to zero and the area associated with the linear portion of the ascending branch from minimum stress to zero, the calculation could be carried out by means of the following equation:

$$
\Delta W_{e} \approx \frac{\Delta \sigma^{2}}{4 E}
$$

where $\Delta \sigma$ is stress range, and $E$ is Young's modulus. The stress range for a specific strain amplitude could be estimated from the cyclic curve, i.e.,

$$
\frac{\Delta \varepsilon}{2}=\frac{\Delta \sigma}{2 E}+\left(\frac{\Delta \sigma}{2 k \prime}\right)^{1 / n \prime}
$$


where $k^{\prime}$ is the cyclic hardening coefficient and $n^{\prime}$ is the cyclic hardening exponent (see Table 3). Once the applied stress was known, the associated elastic strain energy density per cycle could be computed from Equation (3). Thus, based on the energy relationships of Figure 6, we could compute the cumulative total strain energy densities, which allowed the calculation of the corresponding fatigue life from the power function of Figure 5 . The predicted values $\left(\mathrm{N}_{\mathrm{CTSED}}\right)$ for different strain amplitudes of the three high-strength bainitic steels are presented in Table 5. Figure 8 compares the predicted lives with those determined in the experiments. As can be seen, the $\mathrm{N}_{\text {CTSED }}$ values were more accurate than those computed through SWT and Liu criteria (see Figure 7).

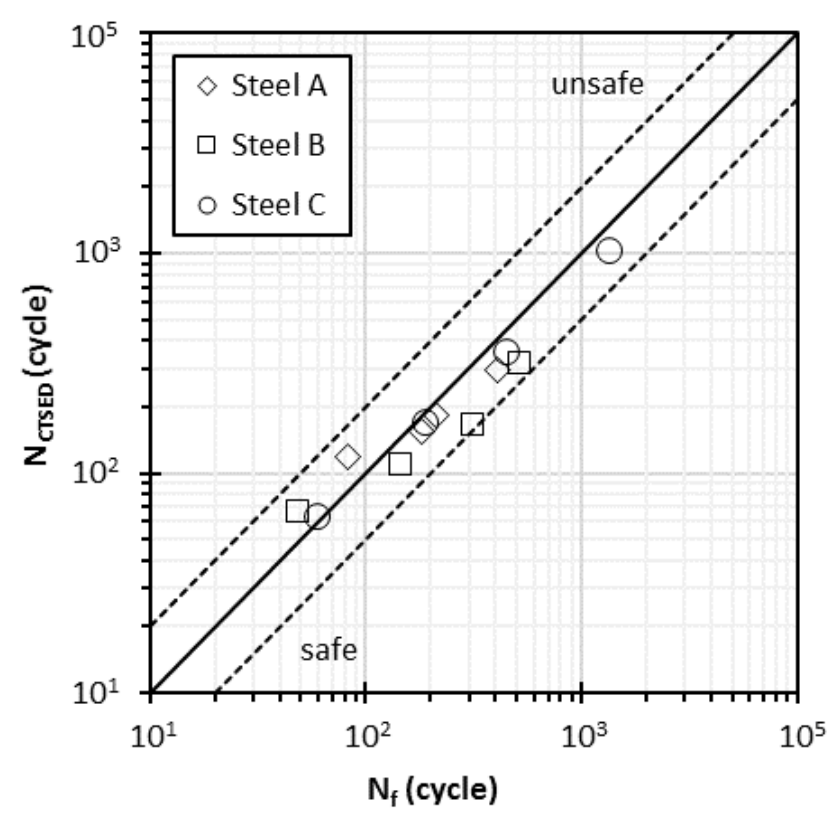

Figure 8. Comparison between numerical and experimental fatigue lives of the proposed model based on the cumulative total strain energy density $\left(\mathrm{N}_{\mathrm{CTSED}}\right)$.

In order to analyze the predictive capabilities of the proposed model in a more systematic manner, probability density functions were used, defined from the following error parameter:

$$
E_{N}=\log _{10}\left(\frac{N_{f}}{N_{p}}\right)
$$

where $N_{p}$ is the predicted lifetime, and $N_{f}$ is the experimental life. In theory, more accurate models are those with lower standard deviations and mean errors close to zero. As shown in Figure 9, the proposed model combined these two features, since it had a mean error closer to zero and a lower standard deviation than the other two. Furthermore, it led to conservative predictions, which was another important outcome. Table 6 presents several statistical parameters computed from the $N_{f} / N_{p}$ ratios obtained for each model, namely minimum error, maximum error, mean, standard deviation and variance. In fact, the cumulative total strain energy density (CTSED) approach led to more accurate results, since its mean deviation was closer to zero and its standard deviation was smaller. 


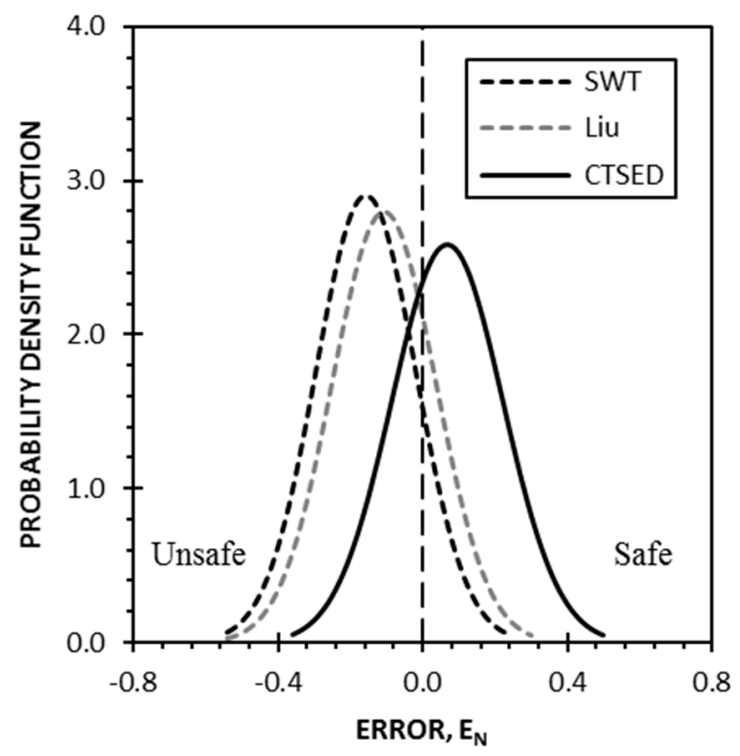

Figure 9. Probability density functions of the SWT, Liu and the cumulative total strain energy density (CTSED) model.

Table 6. Statistical parameters computed from the $\mathrm{E}_{\mathrm{N}}$ values for the three models.

\begin{tabular}{cccccc}
\hline Model & Minimum $N e / N p$ & Maximum $N e / N p$ & Mean & Standard Deviation & Variance \\
\hline SWT & -0.2729 & 0.0700 & -0.1583 & 0.1378 & 0.0189 \\
Liu & -0.2251 & 0.1247 & -0.1068 & 0.1428 & 0.0204 \\
CTSED & -0.1578 & 0.2757 & 0.0682 & 0.1280 & 0.01638 \\
\hline
\end{tabular}

\section{Conclusions}

The present paper studied cumulative strain energy density behavior in three bainitic rail steels with similar chemical compositions but different Mn contents under a symmetric strain-controlled mode. Based on the high correlation between cumulative total strain energy density and fatigue lifetime, a new predictive model, capable of estimating the durability of high-strength bainitic steels, was developed. Predictions were compared to those of the well-known SWT and Liu criteria. The following conclusions can be drawn:

- The cyclic stress-strain response was affected remarkably by Mn content. For each steel, the stress ranges associated with a given strain amplitude were significantly different, as was the shape of the hysteresis loops.

- In the absence of Mn, cumulative plastic strain energy density was higher than cumulative elastic strain energy density. Nevertheless, when Mn content was maximum, opposite behavior was observed.

- $\quad$ Regarding cumulative total strain energy density at higher strain amplitudes, the maximum values were found for the steel with the highest Mn content. On the contrary, at lower strain amplitudes, the maximum $W t$ values were found for the Mn-free bainitic steel.

- A very good correlation between cumulative total strain energy density and fatigue life was found. These two variables were successfully fitted by a single power function independent of Mn content.

- In the form of a power function, a strong correlation between cumulative total strain energy density and elastic strain energy density at the mid-life was found. Nevertheless, in this case, these relationships depended on Mn content. 
- The new model founded on cumulative total strain energy density led to more accurate fatigue life predictions than those of the well-know SWT and Liu criteria, more specifically, lower standard deviations and mean errors closer to zero.

Author Contributions: Conceptualization, R.F.M., R.B. and X.L.; methodology, R.F.M. and R.B.; writing — original draft preparation, R.F.M.; writing—review and editing, R.B., R.F.M.; and X.L.; funding acquisition, X.L. All authors have read and agreed to the published version of the manuscript.

Funding: The authors acknowledge Fundação para a Ciência e a Tecnologia (FCT-MCTES) for its financial support via the project UIDB/00667/2020 (UNIDEMI). The authors also would like to acknowledge the sponsoring under the project number 016713 (PTDC/EMS-PRO/1356/2014) financed by Project 3599 Promover a Produção Científica e Desenvolvimento Tecnológico e a Constituição de Redes Temáticas (3599-PPCDT).

Conflicts of Interest: The authors declare no conflict of interests.

\section{References}

1. Zhou, Q.; Qian, L.; Meng, J.; Zhao, L.; Zhang, F. Low-cycle fatigue behavior and microstructural evolution in a low-carbon carbide-free bainitic steel. Mater. Des. 2015, 85, 487-496. [CrossRef]

2. Li, Y.; Zhang, F.; Chen, C.; Lv, B.; Yang, Z.; Zheng, C. Effects of deformation on the microstructures and mechanical properties of carbide-free bainitic steel for railway crossing and its hydrogen embrittlement characteristics. Mater. Sci. Eng. A 2016, 651, 945-950. [CrossRef]

3. Sawley, K.; Kristan, J. Development of bainitic rail steels with potential resistance to rolling contact fatigue. Fatigue Fract. Eng. Mater. Struct. 2003, 26, 1019-1029. [CrossRef]

4. Aglan, H.A.; Liu, Z.Y.; Hassan, M.F.; Fateh, M. Mechanical and fracture behavior of bainitic rail steel. J. Mater. Process. Technol. 2004, 151, 268-274. [CrossRef]

5. Kumar, A.; Makineni, S.K.; Dutta, A.; Goulas, C.; Steenbergen, M.; Petrov, R.H.; Sietsma, J. Design of high-strength and damage-resistant carbide-free fine bainitic steels for railway crossing applications. Mater. Sci. Eng. A 2019, 759, 210-223. [CrossRef]

6. Long, X.Y.; Zhang, F.C.; Zhang, C.Y. Effect of Mn content on low-cycle fatigue behaviors of low-carbon bainitic steel. Mater. Sci. Eng. A 2017, 697, 111-118. [CrossRef]

7. Gui, X.; Wang, K.; Gao, G.; Misra, R.D.K.; Tan, Z.; Bai, B. Rolling contact fatigue of bainitic rail steels: The significance of microstructure. Mater. Sci. Eng. A 2016, 657, 82-85. [CrossRef]

8. Zhang, F.C.; Long, X.Y.; Kang, J.; Cao, D.; Lv, B. Cyclic deformation behaviors of a high strength carbide-free bainitic steel. Mater. Design 2016, 94, 1-8. [CrossRef]

9. Long, X.Y.; Branco, R.; Zhang, F.C.; Berto, F.; Martins, R.F. Influence of Mn addition on cyclic deformation behaviour of bainitic rail steels. Int. J. Fatigue 2020, 132, 105362. [CrossRef]

10. Georgiev, M.N.; Simeonova, T.V. Railroad rails from bainitic steel. Metal Sci. Heat Treat. 2018, 60, 464-470. [CrossRef]

11. Smith, K.N.; Watson, P.; Topper, T.H. A stress-strain function for the fatigue of metals. J. Mater. 1970, 5, 767-778.

12. Liu, K. A Method Based on Virtual Strain-Energy Parameters for Multiaxial Fatigue Life Prediction. In Advances in Multiaxial Fatigue, 1st ed.; McDowell, D., Ellis, J., Eds.; ASTM International: West Conshohocken, PA, USA, 1993; pp. 67-84.

Publisher's Note: MDPI stays neutral with regard to jurisdictional claims in published maps and institutional affiliations.

(C) 2020 by the authors. Licensee MDPI, Basel, Switzerland. This article is an open access article distributed under the terms and conditions of the Creative Commons Attribution (CC BY) license (http://creativecommons.org/licenses/by/4.0/). 